\title{
TATA SPASIAL ARSITEKTUR TRADISIONAL SUKU ATONI DI KAMPUNG TAMKESI PULAU TIMOR
}

\author{
Reginaldo Ch. Lake \\ Staff Pengajar Prodi. Teknik Arsitektur, Universitas Katolik Widya Mandira \\ Kupang - NTT \\ Email: egilake@yahoo.com
}

\begin{abstract}
Abstrak
Penelitian ini bertujuan untuk menelusuri konsep tata spasial arsitektur tradisional suku Atoni di pulau Timor yakni kampung adat Tamkesi. Metode yang digunakan dalam penelitian ini adalah pertama, menggambar ulang secara dua dimensi dan tiga dimensi lalu kemudian diuraikan berdasarkan pada elemen-elemennya. Penguraian ini perlu dilakukan agar dapat diketahui secara rinci bagaimana hubungan antar seluruh elemen bangunan dan lingkungannya. Kemudian kedua, menganalisis tampilan bentuk.

Analisis berlandas pada elaborasi teori dan paradigma fenomenologi Schulz dan teori ordering principles-Salura.

Berdasar hasil analisis dapat ditelusuri konsep tata spasial arsitektur tradisional yang verstehen tentang budaya bermukim suku Atoni yang mempunyai nilai arsitektur tinggi sampai sekarang.

Hasil penelitian menyimpulkan bahwa relasi tata spasial arsitektur tradisional dipengaruhi oleh konsep hirarki atas-bawah serta adanya pengikat (datum) berupa tata suku, tata gender, persaudaraan etnis, ketaatan tradisi, simbol budaya, spiritual dan menyatu dengan alam.
\end{abstract}

Kata kunci: arsitektur tradisional Tamkesi, tata spasial, ordering principles.

\begin{abstract}
Title: Spatial Planning of Tradisional Architecture as Observed among the Atoni Tribe in the Tamkesi Kampong on Timor Island

This research aims to investigate the concept of spatial planning found in the traditional architecture of the Atoni tribe living in the traditional kampong of Tamkesi on Timor Island. The method employed for this research project consists of the following steps: first of all, to record and re-sketch the entire physical state of this kampong in the greatest possible detail. The result of these sketches is subsequently subjected to an anatomical analysis to arrive a classification of the relationship between all of the elements encountered and scrutinized; secondly, to make an analysis by exposing the latter to the principles of identification and orientation. The analysis is based on an elaboration of the phenomenological approach by Norberg-Schulz and the structural approach involving function-form-meaning by Salura.

Based on the outcome of this analysis, the local concept serves as the basis for the spatial planning of traditional architecture as observed in the Tamkesi kampong. The conclusion drawn reveals that the relationship between the immediate environment, the site, form, framwork and the natural-cultural cycle in traditional architecture is clearly influenced by the concept of top-down (upper vs. lower) hierarchy as well as the binding element (datum) of the tribal order (hierarchy, the gender codeletiquette, ethnic bonds and traditional customs as well as cultural and spiritual symbols).
\end{abstract}

Key words: traditional vernacular architecture Tamkesi, spatial planning, ordering principles. 


\section{Latar Belakang}

Globalisasi yang melanda bidang arsitektur telah terjadi secara intens. Bangunan-bangunan yang muncul pada era ini nyaris mempunyai bentuk dan atribut yang seragam. Paham modernis yang dipicu oleh industrialisasi diyakini melandasi pemikiran terciptanya bahasa univalensi bentuk arsitektur atau lebih dikenal sebagai bahasa "arsitekturinternasional".

Pemunculan arsitektur dengan label bahasa "arsitektur-internasional" ini ternyata mengikis lokalitas dan jatidiri arsitektur ibu pertiwi. Misalnya beberapa bangunan pemerintahan berbentuk geometri kotak yang diselubungi cangkang kaca telanjang berdiri dengan megah sehingga menciptakan satu bentuk tipe saja. Padahal keragaman arsitektur tradisional merupakan suatu keunggulan potensi bahasa arsitektur bila dibandingkan dengan arsitektur dengan label bahasa "arsitekturinternasional". Potensi yang cukup besar menyangkut kearifan lokal arsitektur tradisional adalah pada Daerah Kupang - Nusa Tenggara Timur yang memiliki sepuluh ragam arsitektur tradisionalnya.

Salah satu yang paling menonjol dari sepuluh ragam arsitektur tradisional yang ada adalah arsitektur suku Atoni di kampung Tamkesi. Arsitektur ini merupakan salah satu arsitektur spesifik yang keberadaannya sudah teruji terhadap konteks alam dan budaya setempat selama ratusan tahun. Dengan demikian bahasa arsitektur tradisonal setempat ini perlu dikedepankan dan ditelaah lebih mendalam agar dapat dijadikan sumber rujukan bagi bahasa perancangan arsitektur yang kontekstual. Terlebih lagi penelitian mendalam tentang arsitektur ini termasuk langka.

Berangkat dari potensi dan kelangkaan pengetahuan tentang arsitektur suku Atoni, penelitian ini bertujuan untuk mengungkap seluruh konsep-konsep local-wisdom yang tercipta dari bahasa arsitektur ruang dalam dan luarnya.

Kegunaan dan manfaat yang didapat dari penelitian ini adalah: Pertama, pemahaman yang mendalam mengenai bahasa arsitektur tradisional suku Atoni. Kedua, pemahaman baru tentang metode membaca susunan arsitektur ruang dalam dan luar suku Atoni. Ketiga, pemahaman akan aspekaspek dominan yang melandasi terbentuknya bahasa arsitektur ruang dalam dan luar suku Atoni. Keempat, pentingnya pemahaman bahasa arsitektur suku Atoni untuk digunakan sebagai rujukan bagi terciptanya sintesis antara arsitektur lokal dengan modern.

\section{Metode dan Studi Kasus}

\section{Studi Kasus}

Salah satu kampung adat tertua di Nusa Tenggara Timur khususnya pulau Timor adalah kampung adat Tamkesi. Diperkirakan kampung ini berdiri sejak 1865. Kampung ini berada di desa Tautpah, dusun III Usboko Biboki Selatan, Kabupaten Timor Tengah Utara (TTU). Dalam pendataan Badan Pusat Statistik Kabupaten TTU (2014), Kabupaten ini secara geografis terletak antara $9^{0} 02$ ' 48' LS-9 ${ }^{0} 37$ ' 36" LS dan antara $124^{0} \quad 04^{\prime} \quad 02^{\prime \prime B T-124^{0}} 46^{\prime}$ 00"BT. Batas kampung adat Tamkesi: sebelah Utara dengan desa Tautpah dan Sapaen, sebelah Timur dengan Oekopa dan Oriabesi, sebelah Selatan dengan T'eba dan Sebelah Barat dengan Tokbesi. 
Menurut Laporan Studi Vernakular Unwira (2010, unpublished), kampung Tamkesi merupakan komunitas kecil pada sebagian kecil wilayah desa Tokbesi. Kelompok kecil masyarakat ini bertempat tinggal pada daerah pegunungan atau daerah pedalaman pada masa lalu dikenal sebagai wilayah kerajaan Biboki. Tamkesi adalah bekas istana atau pusat kerajaan Biboki di waktu lampau hingga kini, yang juga disebut Sonaf oleh masyarakat setempat. Di waktu lampau kerajaan ini dipimpin oleh seorang kaiser (kaisar).

Kata Biboki diambil dari nama seorang leluhur asal pulau Timor bagian Timur (Timor Leste). Sang leluhur bernama Usif Biboki, bersama keluarga besarnya di waktu silam merupakan kelompok masyarakat nomaden berpindah-pindah dari sekitar pantai Oepuah hingga menetap di pegunungan sekarang. Konon mereka melakukan pengembaraan ke arah Barat pulau yang sama yang kini menjadi wilayah Nusa Tenggara Timur.

Sampai saat ini kondisi fisik kampung adat Takemsi relatif masih tidak berubah dan penduduknya masih memegang teguh adat istiadatnya. Pokok-pokok inilah yang dijadikan dasar mengapa kampung Takemsi ditentukan sebagai studi kasus penelitian.

\section{Langkah-langkah Analisis}

Langkah awal analisis adalah menentukan alat baca yang sejalan dengan tujuan penelitian dan kespesifikan studi kasus (arsitektur tradisonal). Penelitian-penelitian yang ada sebelumnya menunjukkan bahwa pendekatan struktural dan fenomenologi dianggap sebagai pendekatan yang paling sejalan dengan karaterisitik penelitian. Penelitian yang dilakukan ini mengelaborasi dan menggabungkan pendekatan Norberg Schulz dan Salura. Kemudian berdasar kedua pendekatan yang saling melengkapi di atas disusun sebuah kerangka baca.

Pada intinya Norberg-Schulz (1971), (yang banyak dipengaruhi oleh fenomenologi Heidegger) mengedepankan dua sisi utama yang berinteraksi untuk saling melengkapi. Ia menguraikan bahwa bagaimana momen ruang dan masa digunakan saling terikat dengan asosiasi yang melekat secara eksistensial dalam diri manusia pengamatnya. Lebih lanjut dia memetakan dua sisi utama tadi sebagai: figure-form-space dan memory-identification-orientation.

Sedangkan pendekatan Salura (2001) yang berangkat dari struktur eksistensial fungsi-bentuk-makna meyakini bahwa tarik menarik antara fungsi dan bentuk arsitektur itulah yang dimaknai oleh pengguna dan pengamatnya. Salura menyatakan bahwa dalam diri manusia selalu ada makna keteraturan tentang keseimbangan dan hirarki yang berlandas pada esensi manusia dan alam.

Elaborasi dari kedua pendekatan di atas pada penelitian ini adalah sebagai berikut:

Pada sisi non fisik ditetapkan dua pokok utama yaitu aspek identifikasi dan orientasi yang akan ditelusuri pada sisi fisik kampung Atoni. Sedangkan pada sisi fisik, seperti dijelaskan oleh Salura (2010), maka seluruh massa dan ruang kampung Atoni diurai secara anatomikal seperti: lingkup lingkungan sekitar, lingkup tapak, lingkup bentuk massa dan ruang dalam tapak, lingkup 
sosok pelingkup massa dan ruang, lingkup siklus massa dan ruang (lihat kerangka baca Gambar 1).

Langkah yang dilakukan dalam penelitian ini adalah:

Pertama, merekam secara menyeluruh dengan rinci kondisi dan tatanan fisik yang ada, lalu menggambarkannya kembali baik secara tiga dimensi maupun dua dimensi. Penggambaran ulang ini menjadi penting karena berdasar hasil penggambaran dapat dilakukan pengamatan lanjut secara lebih teoritik.

Kedua, mengklasifikasikan hasil penggambaran fisik tadi berdasar uraian anatomikal di atas.

Ketiga, menghadapkan hasil klasifikasi anatomikal dengan prinsip identifikasi dan orientasi. Pada prinsip identifikasi diteliti apa yang melandasi terciptanya masing-masing klasifikasi, apakah: prinsip sumbu, simetri, datum, ritme. Pada prinsip orientasi ditelusuri: prinsip hirarki atas-bawah, jauh-dekat, kiri-kanan, dan depan-belakang.

Keempat, dominasi prinsip yang didapat pada bagian ketiga, kemudian dihadapkan dengan konsep-konsep lokal yang ada. Pada telaah ini dapat disimpulkan prinsip-prinsip apa saja yang berkaitan erat dengan konsep pembentukan massa dan ruang masyarakat kampung Atoni.

Kelima, konsep-konsep lokal yang berhasil disimpulkan kemudian dilihat kesamaannya pada tiap klasifikasi massa dan ruang. Dengan demikian dapat disimpulkan konsep dominan lokal apa yang melandasi tata spasial kampung Atoni.

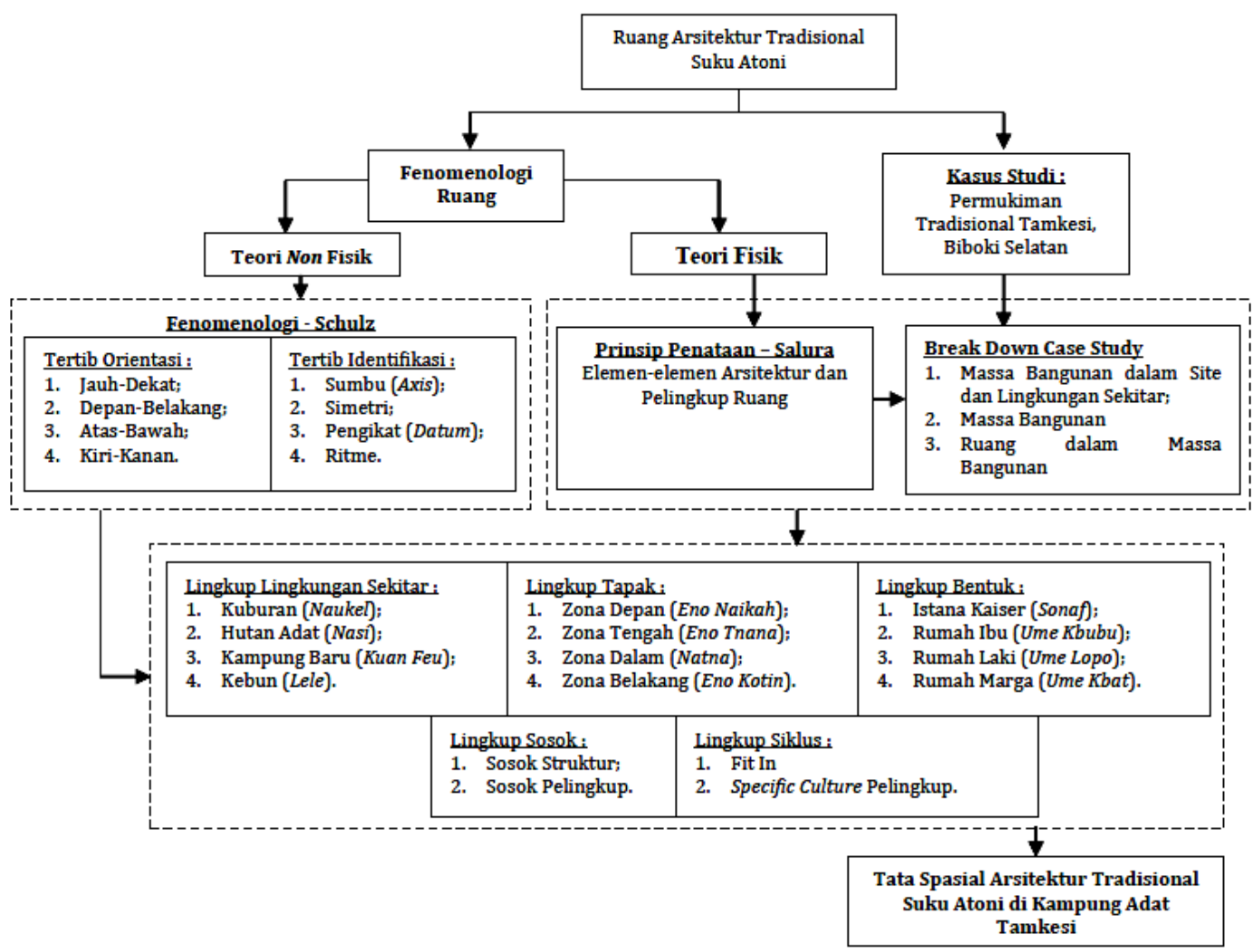

Gambar 1. Kerangka Baca

Sumber: Analisis Penulis, 2013 


\section{Pembahasan}

\section{Pertama, Lingkup Lingkungan Sekitar}

Prinsip Orientasi (Hirarki)

Kampung adat Tamkesi merupakan sentral/bagian utama dengan hirarki penanda ruang luar dari skala lingkungan. Hubungan atau orientasi lingkup lingkungan sekitar (naukel, nasi, kuan feu, dan lele) selalu terkait jarak kedekatan (jauh-dekat) dengan kampung adat Tamkesi sebagai sentral aktivitas adat. Orientasi depanbelakang cenderung mempengaruhi keberadaan kampung baru yang mengadopsi konsep bangunan perkotaan. Bagian sentral (kampung adat Tamkesi) sebagai pusat sonaf Tamkesi mempunyai nilai yang lebih tinggi dari bagian lingkungan sekitar yang mengikat eksistensi ruang luar yang tercipta dari elemen-elemen lingkungan sekitar (naukel, nasi, kuan feu dan lele).

Prinsip Identitfikasi (Part and Whole) Karena mempunyai susunan yang diatur (datum) maka tata spasial (khususnya ruang luar) yang tercipta cenderung formal sesuai dengan aturan adat dan budaya, serta dipengaruhi oleh kondisi alam sekitar. Adanya permukiman adat sebagai wujud ruang inti (suci) yang memungkinkan elemen-elemen pembentuk tata spasial (ruang luar) skala permukiman memiliki orientasi yang sangat jelas yakni mengarah pada satu sumbu (axis) yaitu sonaf Tamkesi. Walaupun kuantitas faktor pengikat (datum) lebih besar dari faktor yang lainnya, tetapi elemen yang muncul dari komunitas perkampungan baru adalah pengulangan (rythm) bangunan segi empat. Elemen yang dominan dalam penciptaan ruang luar permukiman adat Tamkesi berskala lingkup lingkungan sekitar adalah unsur pengikat (datum), baik adat, budaya dan alam.

\section{Kedua, Lingkup Tapak}

Prinsip Orientasi (Hirarki)

Konsep bermukim orang Tamkesi dipengaruhi oleh budaya dan tradisi. Konsep tersebut dimunculkan pada visual pola tata lingkup tapak. Seperti pada bagian analisis sebelumnya jelas bahwa hirarki atas-bawah sangat dominan sebagai ordering principle kampung adat Tamkesi. Bagian atas diyakini sebagai ruang privat dan paling suci (fafon), bagian bawah merupakan ruang publik (ruang profan/munin). Kepositifan hirarki atas-bawah ruang luar dari lingkup tapak ini jelas terjadi interaksi visual antar zona (eno), yang terjadi secara intensif pada perbedaan kontur (level tinggi-rendah zona). Hirarki depanbelakang juga menjadi konsep ordering principles permukiman adat Tamkesi. Konsep bermukim yang bertajuk istana memperhatikan orientasi depan-belakang sebagai konsep pertahanan diri dalam skala bermukim. Hubungan visual pembagian zona depan, tengah, dalam dan belakang menciptakan adanya perhatian penghuni terhadap ruang luar tersebut sehingga menciptakan tanggung jawab terhadapnya. Dengan adanya teritori/zona, maka terciptanya ruang luar yang dikontrol dan dipertahankan oleh penghuni zona, sehingga menimbulkan perasaan memiliki dan menjadi peduli terhadap ruang luar tersebut.

\section{Prinsip Identitfikasi (Part and Whole)}

Lingkup tapak sebagai ruang luar dan pengikat zona. Tingkat kepositifan ruang luar ini tercipta sejalan dengan penciptaan rasa kepemilikan atau teritori penghuni (lian meosopan, lian 
aat, lian atupas, dan nuat) terhadap ruang-ruang luar pada kompleks permukiman Tamkesi. Semakin positif sifat ruang (secara visual nampak pada beda tinggi zona/kontur dan batas teritori berupa dinding batu) semakin kuat rasa kepemilikan yang tercipta terhadapnya. Kepemilikan yang dimaksud bukanlah kepemilikan secara legal, namun berupa kepemilikan secara psikologis adat istiadat yang ditimbulkan juga oleh elemen-elemen pembentuk ruang luar tersebut dalam lingkup tapak (kontur, status jabatan dalam budaya/adat, dan pagar batu/nopon ni nopon. Interaksi secara fisik antara zona dari lingkup tapak terjadi melalui keberadaan pintu masuk setiap zona yang dibatasi oleh susunan batu (nopon ni nopon). Area ini berfungsi sebagai batas/pengikat sekaligus peralihan secara fisik antara ruang luar yang bersifat publik (zona depan/eno naikah) dengan ruang luar yang relatif privat (zona dalam/natnaeno oebnah).

\section{Ketiga, Lingkup Bentuk}

Prinsip Orientasi (Hirarki)

Komposisi bentuk dari massa bangunan arsitektur Tamkesi, bagian depan berupa bukaan pintu (neus mat fa) mempunyai nilai yang lebih tinggi dari bagian bangunan lainnya terkait tertib orientasi. Pada bagian tengah bangunan, bagian paling atas (teot koet' na/komposisi atap dan nete bifolume in sun' na) merupakan bagian dengan hirarki penanda bangunan arsitektur Tamkesi dari skala lingkungan, bagian atas yang tertutup berupa dominasi atap merupakan bagian penanda bangunan dari skala agak dekat ditandai dengan adanya ornamen am ume.
Prinsip Identitfikasi (Part and Whole)

Karena mempunyai susunan berbentuk arch, bangunan arsitektur Tamkesi berkesan dinamis dan ringan. Komposisi pengikat (datum) lebih dominan terutama elemen atapnya yang memenuhi komposisi bentuk bangunan arstiektur Tamkesi, maka bangunan berkesan menyatu dalam satu bentuk dan menjadikan bentuk massa bangunan itu terlihat monumental dari kejauhan. Adanya sumbu (axis) yang memusat pada satu titik di puncak atap sebagai penanda lokalitas dan identitas bangunan arsitektur Tamkesi. Jelas terlihat konsep icon/identitas lokal arsitektur Tamkesi, yang didasari oleh keberadaan massa bangunannya, sekaligus penanda status kepemilikannya.

\section{Keempat, Lingkup Sosok}

Prinsip Orientasi (Hirarki)

Lingkup sosok stuktur dan pelingkup massa bangunan jelas memiliki susunan yang mengarah pada tata atas dan bawah. Bagian atas dari lingkup sosok tersebut menjadi prioritas dalam mewujudkan bentukan arsitektur massa bangunan di Tamkesi. Bagian atas yang menyempit (malelbon) menjadi penanda bangunan dari skala bentuk yang ditandai dengan adanya ornamen am ume. Bagian bawah merupakan bagian yang melebar (mainuabon) yang menyatu dari atas hingga bawah. Hal itu terlihat jelas dari bentuk atap (toet koet na) yang terjuntai hingga ke permukaan tanah.

Prinsip Identitfikasi (Part and Whole)

Karena mempunyai susunan simetri dari lingkup sosok ini, maka massa bangunan cenderung bersifat seimbang, walaupun bentuk massa yang digunakan adalah bentuk-bentuk dinamis yakni bulat dan elips. Elemen atap memiliki kualitas yang besar dan 
menjadi dominan pada massa bangunan dari kejauhan. Walaupun elemen atap mendominasi semua elemen dari sosok massa bangunan tapi elemen pengikat dari setiap lingkup berbeda yakni nopon ni nopon, nabit, dan naoba/sonaf in sun' na. Sedangkan untuk lingkup struktur jelas diikat oleh tiang-tiang agung sebagai unsur terpenting ruang dalam massa bangunan.

\section{Kelima, Lingkup Siklus}

Prinsip Orientasi (Hirarki)

Bentuk, ruang dan tatanan kompleks permukiman adat Tamkesi amat dipengaruhi oleh faktor fisik dan non fisik. Faktor fisik berupa iklim, cuaca, vegetasi dan topologi. Faktor non fisik berupa lingkungan sosial, budaya, kepercayaan dan aktivitas keseharian. Dari analisis fit in dan specific culture jelas bahwa konsep hirarki atas-bawah menjadi komposisi yang dominan baik tanggap terhadap iklim, alam, budaya, religi dan lingkungan sosial. Unsur tertinggi menjadi penanda pada sesuatu yang sakral (fafon) sehingga perlu dihormati dan dihargai dalam adat istiadat orang Tamkesi. Tata suku menjadi peran yang penting dalam budaya bermukim di Tamkesi. Hirarki suku ini memberi orientasi atas dan bawah. Suku Usboko menjadi sangat sentral dan memiliki nilai lebih dari suku lain. Relasi tata suku dan tata ruang terjalin ketika orientasi berpusat pada penanda budaya yaitu upacara adat yang berlangsung di tengah kampung Tamkesi. Orientasi atasbawah sangat dipengaruhi oleh faktor iklim. Bagian atas (berupa bukit) akan terasa aman dibandingkan di bagian bawah berupa lembah di saat musim hujan.

\section{Identitfikasi (Part and Whole)}

Karena permukiman adat Tamkesi terbentuk dari alam, maka segala elemen pembentuk ruang, material dan aktivitas masyarakat adat Tamkesi terikat pada alam. Sedangkan simbol budaya (cultural symbolic) amat terkait dengan konsep kepercayaan (religi). Jadi, pengikat (datum) adalah unsur dominan dalam lingkup siklus yang terpelihara sejak masa leluhur Biboki berupa wujud upacara adat.

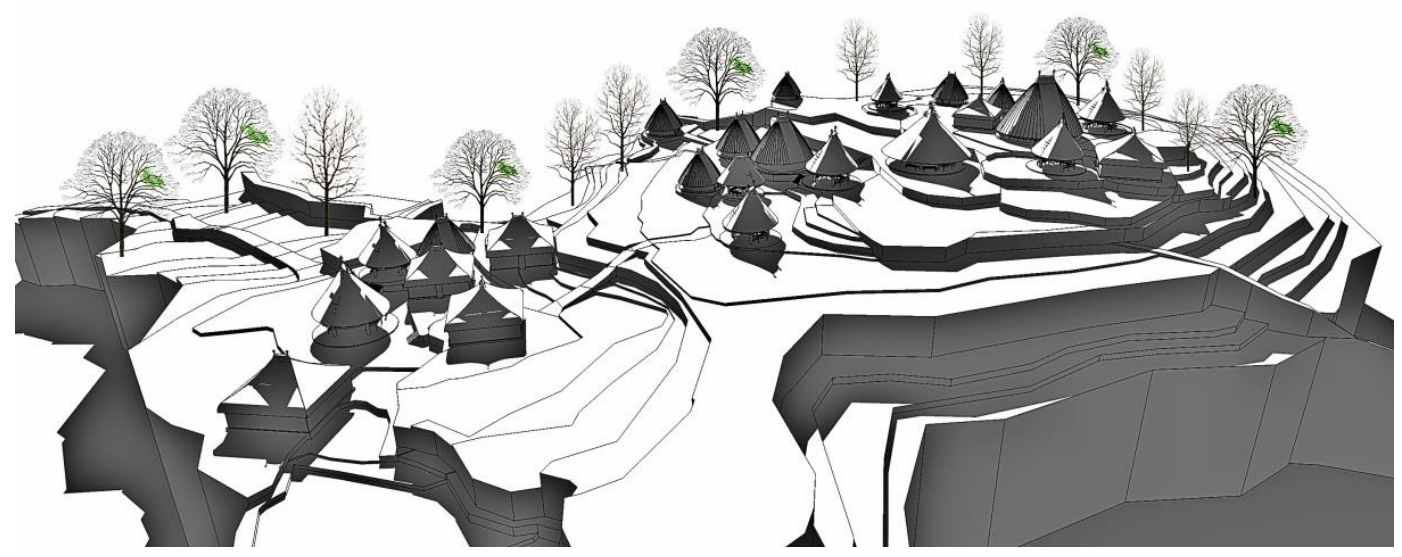

Gambar 2. Isometri Permukiman Tamkesi

Sumber: Analisis Penulis, 2013 


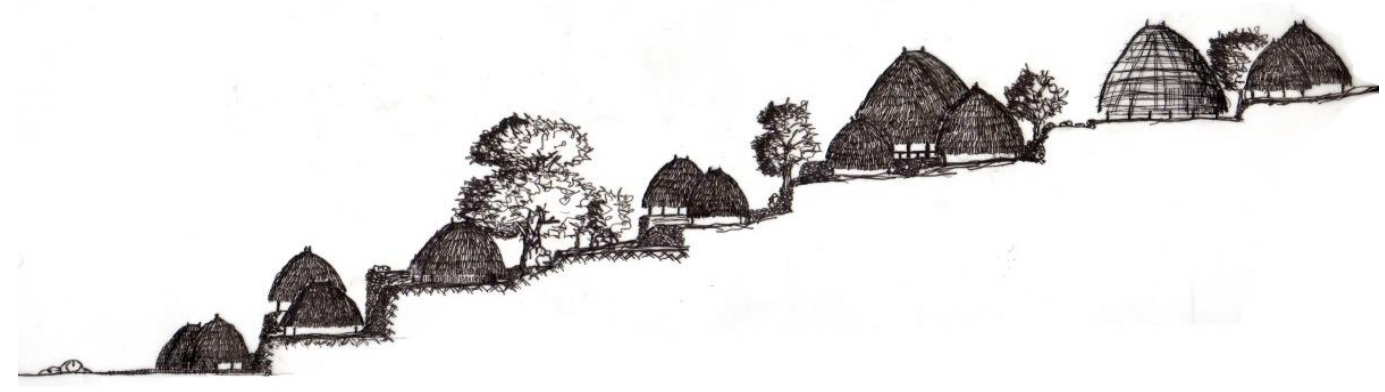

Gambar 3. Potongan Site Permukiman Tamkesi Sumber: Analisis Penulis, 2013
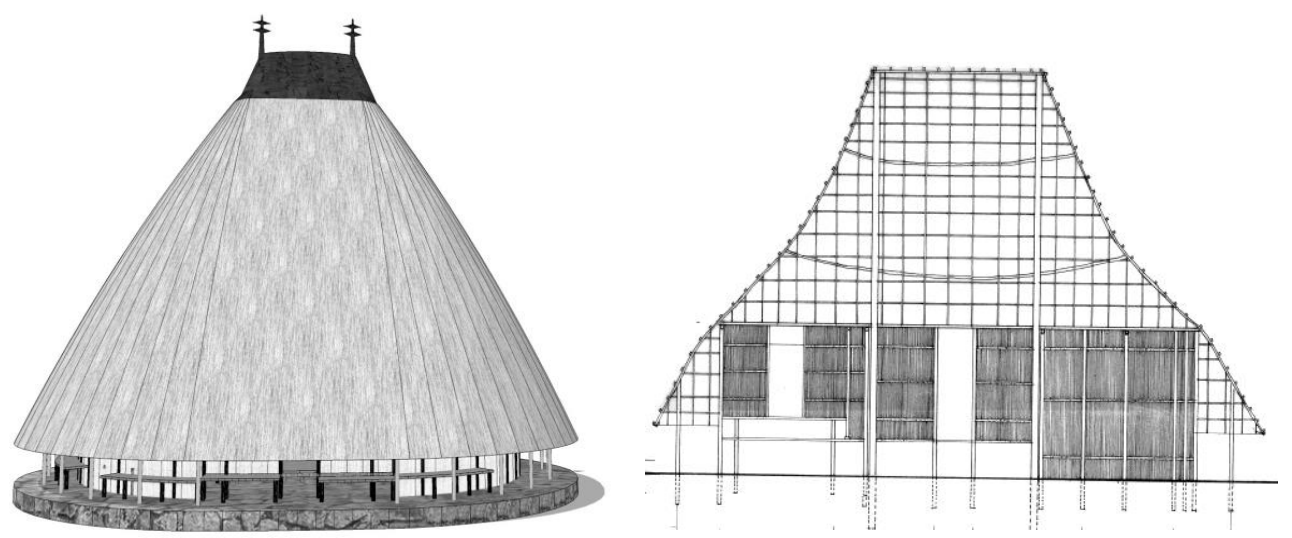

Gambar 4. Sonaf Mnasi, Istana Tamkesi Sumber: Analisis Penulis, 2013
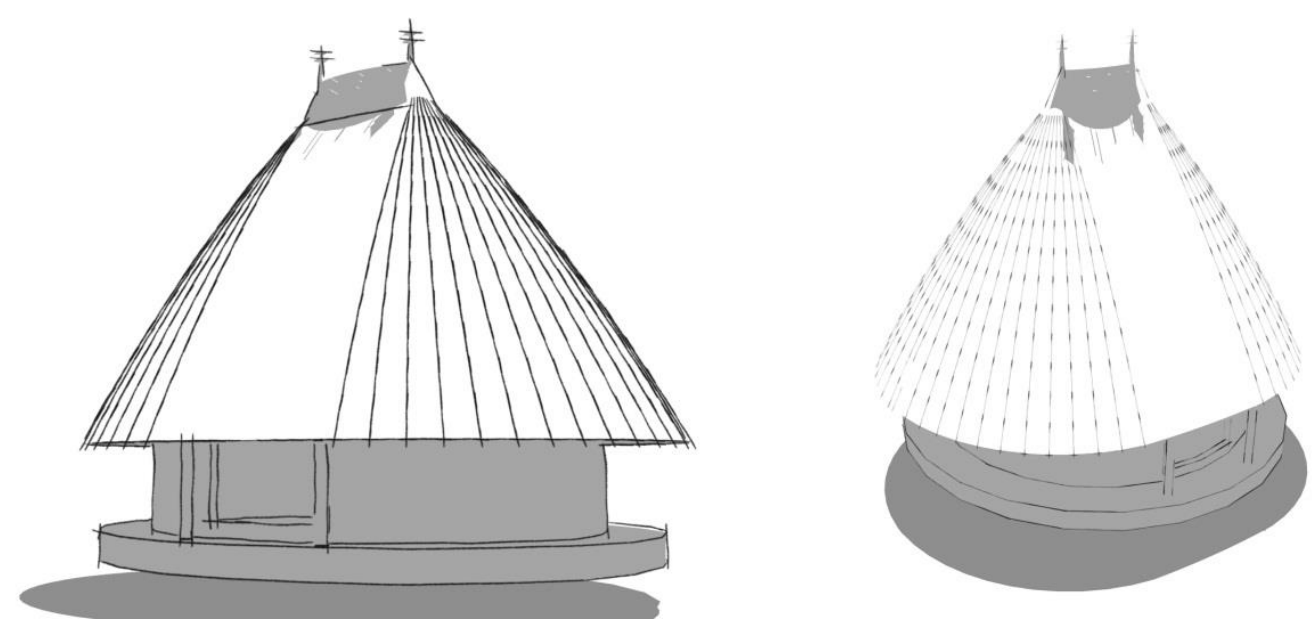

Gambar 5. Ume Kbubu, Rumah Ibu (Lambang Wanita) Sumber: Analisis Penulis, 2013 

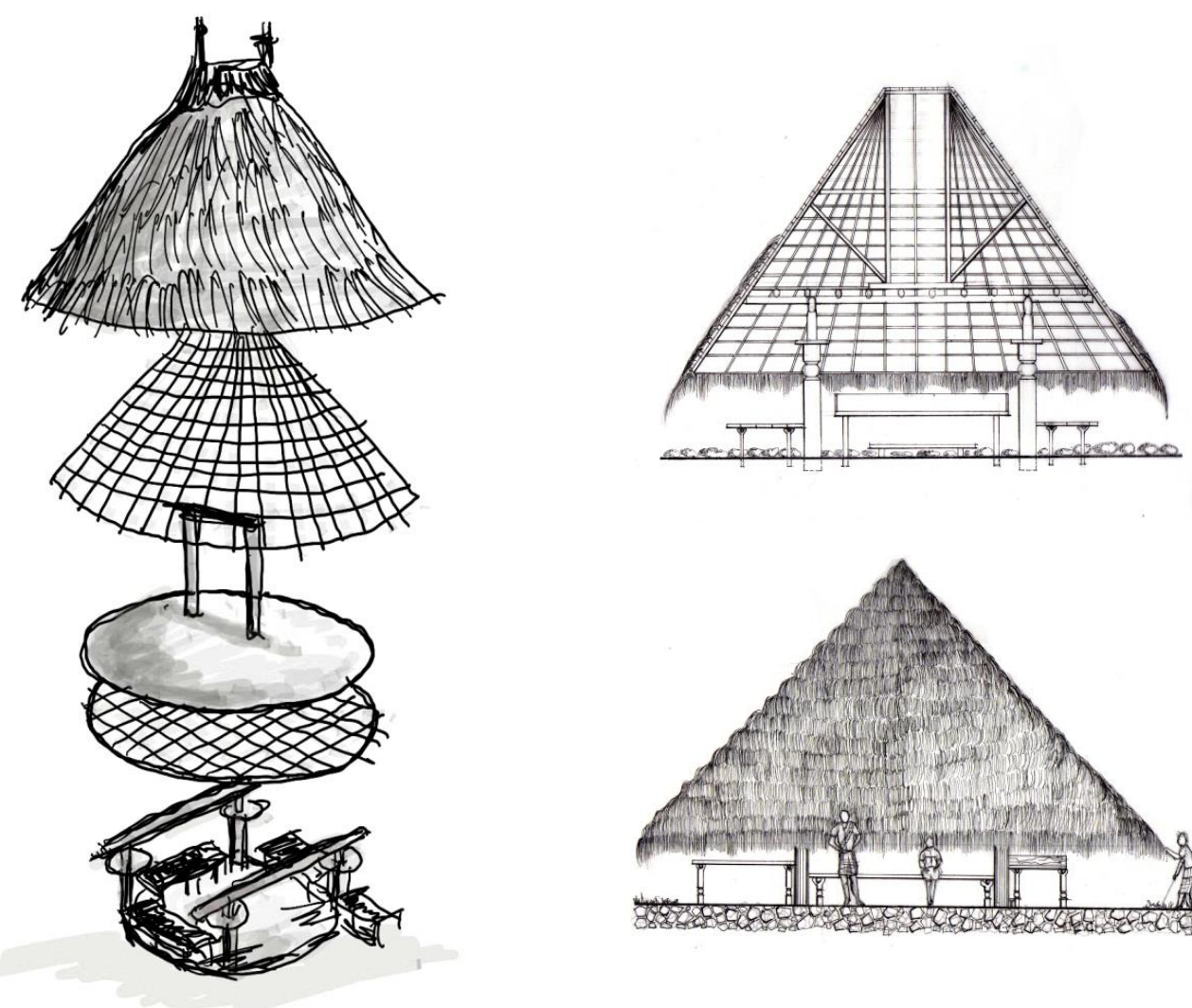

Gambar 6. Ume Lopo, Rumah Laki-Laki

Sumber: Analisis Penulis, 2013
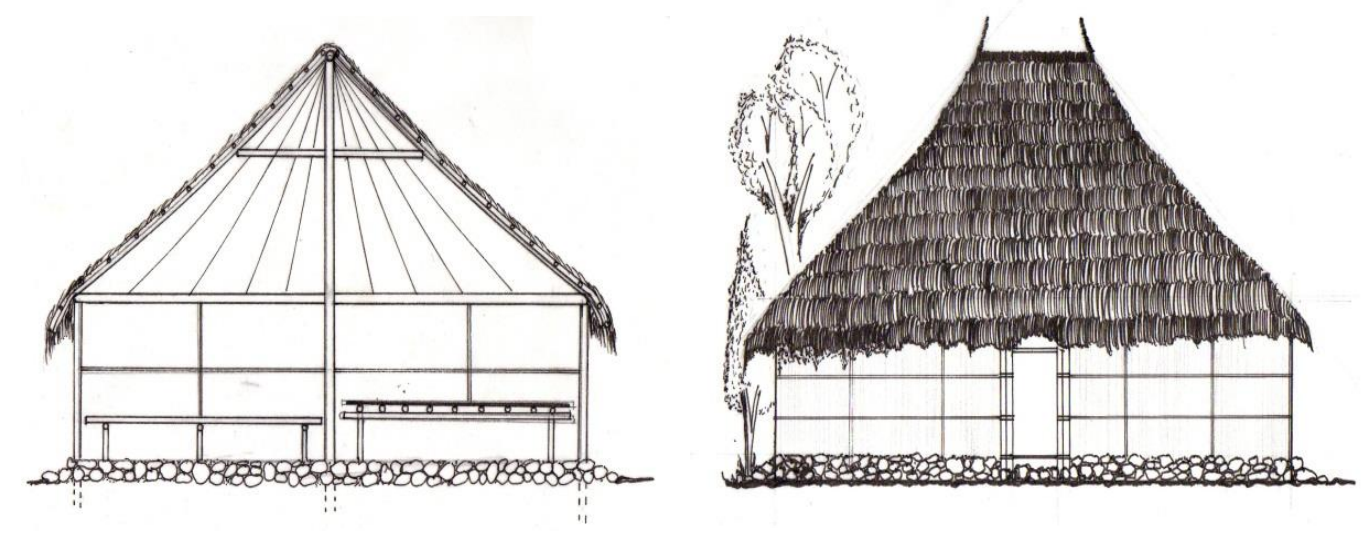

Gambar 7. Ume Kbat/Kanaf, Rumah Suku/Keluarga (Klan)

Sumber: Analisis Penulis, 2013 


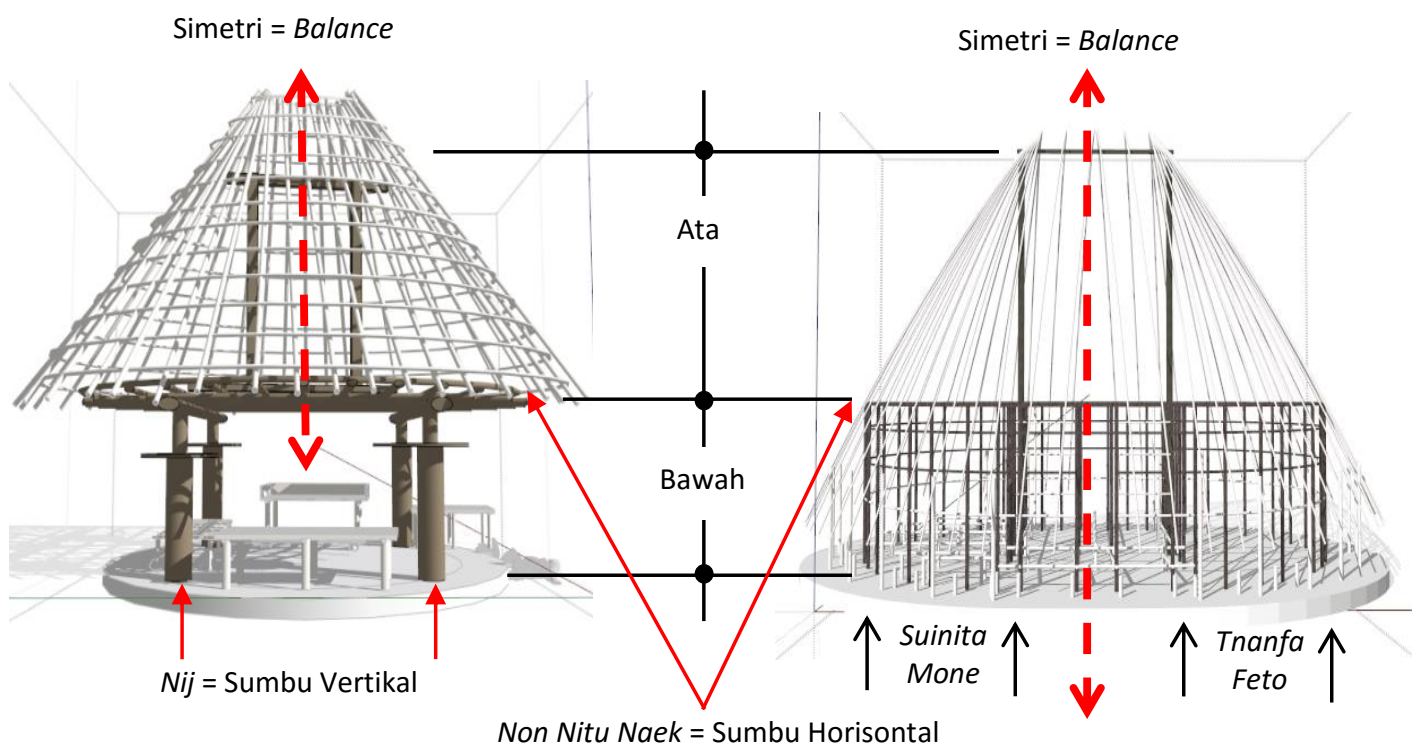

Ume Lopo

Ume Kbubu dan Sonaf

Gambar 8. Komposisi Orientasi dan Identifikasi Massa Bangunan Lopo, Ume Kbubu, dan Sonaf

Sumber: Analisis Penulis, 2013

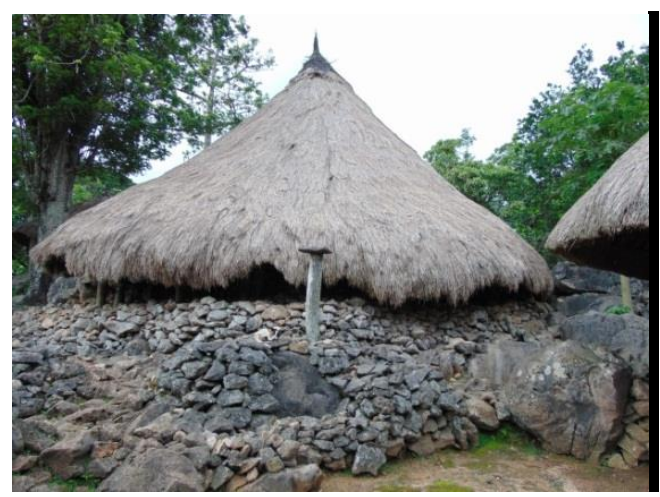

Gambar 9. Sonaf Tamkesi - Biboki Selatan Sumber: Analisis Penulis, 2013

\section{Kesimpulan}

Berdasar hasil analisis dapat disimpulkan bahwa:

Pertama, tata spasial arsitektur tradisional suku Atoni sangat terkait erat dengan konsep penciptaan ruang luar dan relasi dengan ruang dalamnya. Pembentukan kampung Tamkesi dimulai dari penyusunan ruang luar, ruang dalam, dan boundary antar fungsi tradisi. Tipe dan orientasi bangunan rumah-rumah serta sarana

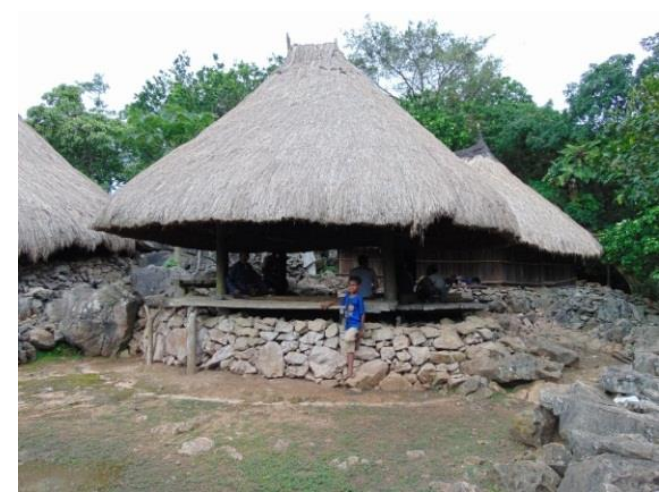

penunjang lainnya berdasar pada konsep ruang luar dan dalamnya.

Kedua, penelitian ini mengedepankan suatu metode yang relatif baru yang merinci membaca kampung Tamkesi berdasar pada klasifikasi anatomi (masa bangunan, ruang dalam dan luar).

Ketiga, Aspek penting dari prinsip orientasi arsitektur tradisional Tamkesi adalah hirarki atas-bawah yakni atas 
sebagai elemen ruang yang disucikan/dihormati sedangkan bawah adalah elemen ruang yang bersifat profan. Konsep dari hirarki atas-bawah tersebut didasari oleh persaudaraan etnis/suku dan relasi dengan alam. Sedangkan aspek penting dari tertib identifikasi adalah pengikat (datum) yakni didasari oleh konsep ketaatan tradisi, simbol budaya dan religi/spiritual dalam wujud upacara adat.

Keempat, pemahaman mendalam tentang tata spasial arsitektur tradisional (ruang dalam dan luar) suku Atoni di Tamkesi dapat digunakan sebagai rujukan untuk merancang arsitektur bagian kota, permukiman baru serta bangunan baru lainnya. Diharapkan proses sintesis antara konsep lokal yang baik dengan teknologi modern dapat tercipta. Dengan demikian pada gilirannya akan terwujud arsitektur yang mengikuti kemajuan jaman sekaligus fit dengan konteks budaya dan alam lokalnya.

\section{Daftar Pustaka}

Badan Pusat Statistik Kabupaten TTU (2014). TTU dalam angka 2013. Dinas BPS Provinsi NTT.

Laporan Studi Vernakular (2010). Program Studi Teknik Arsitektur, Fakultas Teknik, Universitas Katolik Widya Mandira, Kupang (tidak dipublikasikan).

Norberg-Schulz, C. (1971). Existence, space and architecture. Praeger Publishers.

Salura, P. (2001). Ber-arsitektur: Membuat, menggunakan, mengalami dan memahami arsitektur. Bandung: Architecture \& Communication.
Salura, P. (2010). Arsitektur yang membodohkan. Bandung: Cipta Sastra Salura. 